Short Paper

\title{
Preparation and Purification of DHA-enriched Triacylglycerols from Fish Oils by Column Chromatography
}

\author{
Kenji Hayashi and Hideki Kishimura \\ Faculty of Fisheries, Hokkaido University, Hakodate, Hokkaido 041, Japan \\ (Received November 9, 1995)
}

Key words: column chromatography, fish oil, triacylglycerol, docosahexaenoic acid

The $n-3$ polyunsaturated fatty acids in fish oils, especially icosapentaenoic (EPA; 20:5n-3) and docosahexaenoic (DHA; 22:6n-3) acids, are effective in lowering serum cholesterol and triacylglycerol (TG) levels and inhibiting platelet aggregation and blood clotting, thereby reducing the risk of heart attacks. ${ }^{1)}$ It was also suggested that DHA may play an important physiological role for the brain and retina of mammals. ${ }^{2)}$ Additionally, it was recognized that absorption of EPA or DHA in a TG form was more advantageous than in an ethyl ester form in human subjects. ${ }^{3)}$ We have recently investigated the preparative scale isolation of EPA-highly enriched TGs from the scallop hepatopancreas lipids by using a silicic acid column chromatographic technique.4) On the other hand, the orbital tissue oils of skipjack and/or tuna were a good source of DHA-containing TGs. ${ }^{5,6)}$ In the present study, we report a simple column chromatographic method for the enrichment of the DHA-containing TGs from crude fish oils. Different orbital tissue oils from skipjack Euthynnus pelamis, southern bluefin tuna Thunnus maccoyi, and bigeye tuna $T$. obesus, were chosen to demonstrate the quantitative separation of DHA-enriched TGs from the original fish oil TGs with various molecular weights and degrees of unsaturation.

Lipid extraction and analysis were performed as described in a previous report. ${ }^{7}$ Analysis of fatty acid methyl esters was carried out using a Shimadzu GC14A gas chromatograph equipped with a $30 \mathrm{~m} \times 0.25 \mathrm{~mm}$ I.D. UlbonHR-20M column (Shinwa Chemical Industries Ltd.) and a flame ionization detector. Helium was used as the carrier gas. The column oven was held for $5 \mathrm{~min}$ at $160^{\circ} \mathrm{C}$ and then programmed at $4^{\circ} \mathrm{C} / \mathrm{min}$ to $230^{\circ} \mathrm{C}$, and subsequently held at the final temperature for $30 \mathrm{~min}$. The yields of the fish oils were $48.7 \%$ for skipjack $(n=6), 83.5 \%$ for southern bluefin tuna $(n=1)$, and $81.1 \%$ for bigeye tuna $(n=2)$ in wet orbital tissue weight. These orbital tissue oils were characterized by a high level of TGs (mean \pm standard deviation; $97.9 \pm 1.3 \%$ ) with small amounts of sterols $(1.1 \pm 1.0 \%)$ and phosholipids $(0.9 \pm 0.4 \%)$. The component fatty acids of the original TGs in these fish oils contained saturates $(29.9 \pm 0.9 \%)$ with $16: 0(20.0 \pm 0.9 \%)$, $14: 0(3.9 \pm 0.7 \%)$, and $18: 0(3.6 \pm 0.6 \%)$, monoenes $(31.9 \pm 4.1 \%) \quad$ with $18: 1 n-9 \quad(18.1 \pm 3.4 \%), \quad 16: 1 n-7$ $(6.0 \pm 0.6 \%)$, and $18: \ln -7(2.6 \pm 0.3 \%)$, and polyenes $(36.3 \pm 3.5 \%)$ with DHA $(20.4 \pm 2.4 \%)$ and EPA $(7.3 \pm 1.9 \%)$.
An aliquot $(4,038 \pm 27 \mathrm{mg})$ of the orbital tissue oils was dissolved in a small volume of $n$-hexane and applied to a column $(160 \mathrm{~g}, \phi 3.1 \times \mathrm{ca} 47 \mathrm{~cm})$ of silicic acid (Wakogel C-200)-celite 545 (2:1 w/w, Wako Pure Chemical Industries Ltd.) which was activated for $5 \mathrm{~h}$ at $110^{\circ} \mathrm{C}$ and packed with $n$-hexane. Step-wise elution was done with $n$ hexane $(360 \mathrm{ml}), 5 \%$ of diethyl ether in $n$-hexane $(1,800$ $\mathrm{m} l), 10 \%$ of diethyl ether in $n$-hexane $(720 \mathrm{~m} l)$, diethyl ether $(360 \mathrm{ml})$, and methanol $(720 \mathrm{ml})$ in that order. Fractions of each of $360 \mathrm{~m} l$ eluents were collected at the flow rate of ca $3 \mathrm{~m} / / \mathrm{min}$ and subjected to thin-layer chromatography (TLC) for identification of TG types. All of the six fractions which were eluted with $5 \%$ of diethyl ether in $n$-hexane (frs. 3 to 7 ) and with $10 \%$ of diethyl ether in $n$-hexane (fr. 8) contained only TGs, not contaminating other lipid types. Elution sequence and fatty acid profiles of TGs separated from the different orbital tissue oils by silicic acid column chromatography are given in Table 1. Rf values of the separated TGs in TLC were gradually reduced in their order of separation. These TGs were differentiated from each other by degree of unsaturation of the component fatty acids, corresponding to a gradual decrease in saturates and monoenes and to a gradual increase in polyenes. This result was in agreement with that reported previously by Mangold and Malins. ${ }^{8}$ Also, the unsaturation indices of the TGs in the different fish oil fractions increased linearly (regression coefficient; $r=0.997$ ) in their order of separation. The separation of these TGs according to degree of unsaturation presumably was due to the polarity of double bonds in the component unsaturated fatty acids. The separated TGs largely consisted of saturated and monoenoic fatty acids with 16:0, 18:0, 18:1n-9, $18: 1 \mathrm{n}-7$, and $20: 1 \mathrm{n}-9$ for frs. 3 to 5 , and of polyenoic ones with DHA, EPA, and $18: 4 n-3$ for frs. 6 to 8 . This was specially true for the TGs in frs. 6,7 , and 8 which contained a large amount of DHA, corresponding to 28.5 , 31.4 , and $35.0 \%$, respectively. The TGs in these three fractions accounted for $28.4 \%$ of the original fish oils, thus DHA in the TGs being concentrated 2.4- to 2.9-fold. TGs in fr. 8 contained considerably large amounts of both DHA (35.0\%) and EPA (22.2\%). Finally, the yellowish brown orbital tissue oils $(4.00 \mathrm{~g})$ gave two fractions containing 0.38 and $0.24 \mathrm{~g}$ of the pale yellow purified TGs with 31.4 and $35.0 \%$ DHA, respectively. For separating fish oil TG molecules according to degree of unsaturation, Dolev and Olcott ${ }^{9)}$ used a column of silica gel impregnated 
Table 1. Elution sequence and fatty acid profiles of triacylglycerol fractions separated from fish oils by column chromatography

\begin{tabular}{|c|c|c|c|c|c|c|}
\hline & \multicolumn{6}{|c|}{ Fraction no. } \\
\hline & 3 & 4 & 5 & 6 & 7 & 8 \\
\hline Yield mg & $319 \pm 91$ & $1384 \pm 128$ & $923 \pm 34$ & $525 \pm 17$ & $380 \pm 21$ & $248 \pm 33$ \\
\hline$\%^{* 1}$ & $7.9 \pm 2.3$ & $34.3 \pm 3.1$ & $22.9 \pm 0.8$ & $13.0 \pm 0.5$ & $9.4 \pm 0.5$ & $6.0 \pm 0.8$ \\
\hline \multicolumn{7}{|c|}{ Fatty acid $\%{ }^{* 2}$} \\
\hline $14: 0$ & $2.8 \pm 0.3$ & $3.6 \pm 0.8$ & $4.4 \pm 0.8$ & $4.3 \pm 0.8$ & $3.8 \pm 0.6$ & $2.7 \pm 0.3$ \\
\hline $16: 0$ & $22.5 \pm 1.9$ & $22.6 \pm 2.2$ & $20.8 \pm 1.0$ & $17.6 \pm 1.2$ & $14.1 \pm 0.7$ & $8.0 \pm 1.3$ \\
\hline 18:0 & $5.5 \pm 1.2$ & $4.5 \pm 0.8$ & $3.1 \pm 0.6$ & $2.3 \pm 0.4$ & $1.6 \pm 0.3$ & $0.4 \pm 0.1$ \\
\hline $16: \ln -7$ & $4.9 \pm 0.8$ & $6.1 \pm 0.7$ & $7.0 \pm 0.6$ & $6.9 \pm 0.7$ & $6.6 \pm 0.4$ & $5.2 \pm 0.9$ \\
\hline $18: \ln -9$ & $25.9 \pm 2.9$ & $23.6 \pm 3.6$ & $16.6 \pm 3.7$ & $12.1 \pm 2.6$ & $8.9 \pm 1.8$ & $5.0 \pm 1.8$ \\
\hline $18: \ln -7$ & $3.3 \pm 0.2$ & $3.2 \pm 0.3$ & $2.6 \pm 0.3$ & $2.1 \pm 0.3$ & $1.7 \pm 0.2$ & $1.0 \pm 0.2$ \\
\hline $20: 1 \mathrm{n}-9$ & $3.9 \pm 2.1$ & $2.5 \pm 1.1$ & $1.1 \pm 0.4$ & $0.6 \pm 0.2$ & $0.3 \pm 0.2$ & $0.1 \pm 0.1$ \\
\hline $18: 4 n-3$ & nd & $0.2 \pm 0.1$ & $0.6 \pm 0.4$ & $1.2 \pm 0.7$ & $2.2 \pm 1.1$ & $4.4 \pm 2.2$ \\
\hline $20: 5 n-3$ & $1.8 \pm 0.2$ & $3.2 \pm 0.6$ & $7.3 \pm 1.8$ & $11.4 \pm 2.6$ & $15.3 \pm 2.8$ & $22.2 \pm 3.8$ \\
\hline $22: 5 n-3$ & $0.4 \pm 0.2$ & $0.7 \pm 0.3$ & $1.3 \pm 0.5$ & $1.8 \pm 0.7$ & $2.1 \pm 0.7$ & $2.7 \pm 0.9$ \\
\hline $22: 6 n-3$ & $12.0 \pm 1.9$ & $15.0 \pm 1.5$ & $23.0 \pm 2.4$ & $28.5 \pm 1.1$ & $31.4 \pm 2.2$ & $35.0 \pm 2.6$ \\
\hline Saturates & $34.3 \pm 2.8$ & $33.6 \pm 2.9$ & $30.4 \pm 1.5$ & $25.9 \pm 1.4$ & $20.9 \pm 0.7$ & $12.1 \pm 1.4$ \\
\hline Monoenes & $44.6 \pm 4.3$ & $39.6 \pm 4.5$ & $29.1 \pm 4.8$ & $23.1 \pm 3.4$ & $18.8 \pm 2.3$ & $12.5 \pm 3.2$ \\
\hline Polyenes & $18.8 \pm 3.1$ & $24.7 \pm 1.4$ & $39.1 \pm 3.3$ & $49.8 \pm 2.6$ & $58.5 \pm 1.6$ & $72.1 \pm 4.1$ \\
\hline Branched & $1.0 \pm 0.1$ & $1.0 \pm 0.1$ & $0.6 \pm 0.1$ & $0.3 \pm 0.1$ & $0.6 \pm 0.2$ & $1.0 \pm 0.9$ \\
\hline Total UI*3 & $134.6 \pm 7.0$ & $168.9 \pm 3.7$ & $236.4 \pm 13.9$ & $288.8 \pm 10.2$ & $327.7 \pm 4.2$ & $391.1 \pm 13.8$ \\
\hline
\end{tabular}

Values are the mean \pm standard deviation of 3 samples. nd; not detectable.

*1 \% to fish oils $(4,038 \pm 27 \mathrm{mg})$ obtained from the orbital tissues of skipjack, southern bluefin tuna, and bigeye tuna.

*2 Data are expressed as weight percentage of total fatty acids.

* Unsaturation index (UI) $=$ fatty acid $\% \times$ number of fatty acid double bond.

with silver nitrate and Laakso et al. ${ }^{10)}$ utilized silver ion high-performance liquid chromatography. Silicic acid column chromatography used in this study is a simple technique for separating DHA-enriched TGs and applicable for large-scale production of these compounds from the orbital tissue oils of skipjack and/or tuna.

\section{References}

1) K. K. Carroll and C. J. H. Woodward: in "Marine Biogenic lipids, Fats, and Oils Vol. II" (ed. by R. G. Ackman), CRC Press, Florida, 1989, pp. 435-456.

2) K. Yazawa and H. Kageyama: Yukagaku, 40, 974-978 (1991) (in Japanese).

3) L. D. Lawson and B. G. Hughes: Biochem. Biophys. Res, Com- mun., 152, 328-335 (1988).

4) K. Hayashi: Nippon Suisan Gakkaishi, 57, 2159 (1991).

5) T. Watanabe, K. Sugii, J. Yamada, T. Kinumaki, and M. Takeuchi: Bull. Tokai Reg. Fish. Res. Lab., 127, 69-80 (1989) (in Japanese).

6) T. Sawada, K. Takahashi, and M. Hatano: Nippon Suisan Gakkaishi, 59, 285-290 (1993) (in Japanese).

7) K. Hayashi and H. Kishimura: Nippon Suisan Gakkaishi, 57, $1397-$ 1401 (1991).

8) H. K. Mangold and D. C. Malins: J. Amer. Oil Chem. Soc., 37, 383-385 (1960).

9) A. Dolev and H. S. Olcott: J. Amer. Oil Chem. Soc., 42, 1046-1051 (1965).

10) P. Laakso, W. W. Christie, and J. Pettersen: Lipids, 25, 284-291 (1990). 